\section{Arginine methylation of MRE11 by PRMT1 is required for DNA damage checkpoint control}

\author{
François-Michel Boisvert, ${ }^{1}$ Ugo Déry, ${ }^{2}$ \\ Jean-Yves Masson, ${ }^{2}$ and Stéphane Richard ${ }^{1,3}$
}

${ }^{1}$ Terry Fox Molecular Oncology Group, Bloomfield Center for Research on Aging, Lady Davis Institute for Medical Research and Departments of Oncology and Medicine, McGill University, Montréal, Québec H3T 1E2, Canada; ${ }^{2}$ Genome Stability Laboratory, Laval University Cancer Research Center, Hôtel-Dieu de Québec (CHUQ), Québec, Québec G1R 2J6, Canada

The role of protein arginine methylation in the DNA damage checkpoint response and DNA repair is largely unknown. Herein we show that the MRE11 checkpoint protein is arginine methylated by PRMT1. Mutation of the arginines within MRE11 severely impaired the exonuclease activity of MRE11 but did not influence its ability to form complexes with RAD50 and NBS1. Cells containing hypomethylated MRE11 displayed intra-S-phase DNA damage checkpoint defects that were significantly rescued with the MRE11-RAD50-NBS1 complex. Our results suggest that arginine methylation regulates the activity of MRE11-RAD50-NBS1 complex during the intra-S-phase DNA damage checkpoint response.

Supplemental material is available at http://www.genesdev.org.

Received November 15, 2004; revised version accepted January 24, 2005.

Protein arginine methylation is a post-translational modification that results in symmetrical or asymmetrical dimethylarginines (sDMA, aDMA) (Gary and Clarke 1998). In humans, protein arginine methyltransferases (PRMT) represent a family of eight known enzymes that utilize S-adenosyl methionine (AdoMet) as a methyl donor (McBride and Silver 2001). The substrates of these PRMT include glycine arginine-rich (GAR) nucleic acidbinding proteins (Gary and Clarke 1998). Arginine methylation has been shown to regulate nuclear export (Yu et al. 2004), nuclear import (Yun and Fu 2000), proteinprotein interactions (Bedford et al. 2000), ribosome biogenesis (Bachand and Silver 2004; Swiercz et al. 2005), pre-mRNA splicing (Friesen et al. 2001; Boisvert et al. 2002), transcriptional elongation (Kwak et al. 2003), and transcription (Chen et al. 1999; Wang et al. 2001, 2004; Rezai-Zadeh et al. 2003; Cuthbert et al. 2004). However, it is not known whether arginine regulates cell cycle checkpoints and the DNA damage response.

[Keywords: MRE11; arginine methylation; DNA repair; PRMT1] ${ }^{3}$ Corresponding author.

E-MAIL stephane.richard@mcgill.ca; FAX (514) 340-8295.

Article published online ahead of print. Article and publication date are at http://www.genesdev.org/cgi/doi/10.1101/gad.1279805.
DNA double-strand breaks (DSB) are a common form of damage that occurs due to external factors such as ionizing radiation or exposure to certain chemicals. Failure to properly repair the damaged DNA results in genetic instability, which can ultimately lead to cancer. Genetic defects underlying chromosomal instability include ataxia-telangiectasia (A-T), A-T-like disorders (ATLD), and Nijmegen breakage syndrome (NBS) (Shiloh 2003). Patients with any one of these disorders exhibit hypersensitivity to ionizing radiation, immunodeficiency, and an increased predisposition to the development of malignancies. These phenotypic outcomes indicate that ATM, MRE11, and NBS1, the gene products deficient in A-T, A-TLD, and NBS, respectively, play an important role in maintaining genomic integrity (Savitsky et al. 1995; Carney et al. 1998; Varon et al. 1998; Stewart et al. 1999). A biochemical link between DSB repair and mammalian cellular responses to DNA damage was uncovered by the observation that NBS1 functions in a complex with the highly conserved DSB repair proteins MRE11 and RAD50 (Carney et al. 1998). The MRE11/RAD50/NBS1 (MRN) complex is known to be involved in the DNA damage response (Stewart et al. 1999; Carson et al. 2003; Theunissen et al. 2003; Uziel et al. 2003; van den Bosch et al. 2003; Lee and Paull 2004). Upon exposure to ionizing radiation, the MRN complex becomes rapidly associated with the DNA DSBs at radiation-induced nuclear foci and remains at these sites until the damage is repaired (Nelms et al. 1998; Lisby et al. 2004). MRE11 is a conserved protein with an N-terminal nuclease domain (Paull and Gellert 1998), as well as a C-terminal DNA-binding region (de Jager et al. 2001; Hopfner et al. 2002) and a GAR domain of unknown function.

Herein, we report that MRE11 contains aDMA within its GAR domain and is a substrate of PRMT1. We show that the GAR domain regulates the exonuclease activity of MRE11. Cells treated with methylase inhibitors, cells treated with PRMT1 siRNA, and PRMT1 $1^{-/}$cells displayed DNA damage-induced intra-S-phase checkpoint defects. This phenotype was significantly rescued by the addition of purified MRE11-RAD50-NBS1 complex. Our findings identify a novel role for protein arginine methylation in the regulation of the DNA damage response.

\section{Results and Discussion}

\section{A novel aDMA-specific antibody recognizes MRE11}

To study the role of methylated arginines and find new proteins containing this modification, an aDMA-specific antibody, named ASYM25, was raised using the GAR peptide N-KFRGGGRGGGRGGFGGRGGRGG-C, where all the arginines were aDMA. Purified ASYM25 recognized the immunizing aDMA-containing GAR peptide and not the unmehtylated or sDMA-methylated GAR peptides (Supplementary Fig. 1A). To identify proteins specifically immunoprecipitated by ASYM25, a largescale immunoprecipitation was performed with HeLa cells followed by MALDI-TOF mass spectrometry identification of the trypsin-digested proteins. A representative immunoprecipitation using ASYM25 on total cell lysates labeled with ${ }^{35} \mathrm{~S}$-methionine revealed many proteins that are specifically immunoprecipitated by the 
antibody (Supplementary Fig. 1B). A protein with an apparent molecular mass of $85 \mathrm{kDa}$ was identified as MRE11 (Boisvert et al. 2003). MRE11 contains multiple repeated arginine and glycine residues between amino acids 566 and 600 constituting a GAR domain. The function of the MRE11 GAR domain and its post-translational regulation are unknown. To confirm that MRE11 can be recognized by ASYM25, HeLa cell extracts were immunoprecipitated with control, ASYM25, and SYM10 antibodies; the latter is an sDMA-specific antibody (Boisvert et al. 2003). MRE11 was detected in ASYM25 but not SYM10 immunoprecipitations, as visualized by immunoblotting with anti-MRE11 antibodies (Fig. 1A). Moreover, immunoprecipitated MRE11 was directly recognized by ASYM25 and not by SYM10 (Fig. 1B). These findings confirm that MRE11 contains aDMA and is the component of the MRN complex that is directly recognized by ASYM25.

The presence of methylated arginines in MRE11 was also analyzed by mass spectrometry. We raised an MRE11 antibody to purify sufficient amounts of MRE11 from HeLa cells. The immunopurified MRE11 was separated by SDS-PAGE, visualized with Coomassie blue, excised as a distinct band of $\sim 85 \mathrm{kDa}$, digested with trypsin, and analyzed by MALDI-TOF mass spectrometry. The mass of 28 tryptic peptides matched MRE11 predicted peptides (Supplementary Fig. 2; Supplementary Table 1). Peptides had additional mass corresponding to the presence of methyl groups and based on the predicted versus observed tryptic peptide masses; it was calculated that nine arginines from MRE11 residues 566-600 were dimethylated (Supplementary Table 1). Collectively, our data show that MRE11 contains aDMAs within its GAR domain residing between residues 566 and 600 .

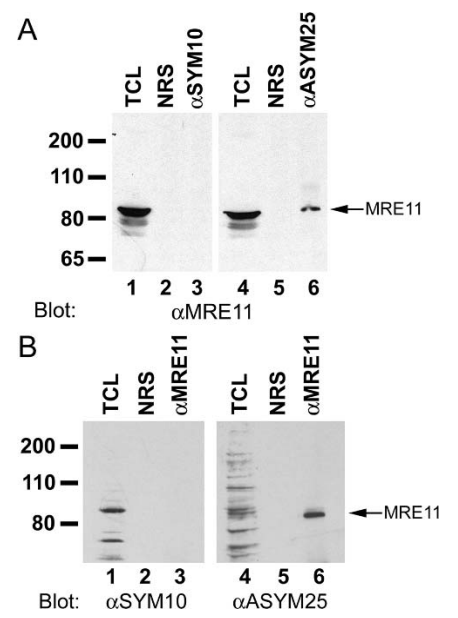

Figure 1. MRE11 contains asymmetrically dimethylated arginines. (A) Antibodies recognizing sDMA (SYM10) or aDMA (ASYM25) were used to perform immunoprecipitations from HeLa cell extracts and, after washing, bound proteins were analyzed by Western blotting to detect MRE11. The total cell lysate (TCL) shows $10 \%$ of the extract used in each binding assay. The migration of MRE11 is indicated on the right. The molecular mass markers are shown on the left in kilodaltons. Normal rabbit serum (NRS) was used as a negative control. (B) MRE11 was immunoprecipitated from HeLa cell extracts and, after washing, bound proteins were analyzed by immunoblotting using SYM10 and ASYM25. Many methylated proteins are visualized in the TCL, and the migration of MRE11 is shown with an arrow.
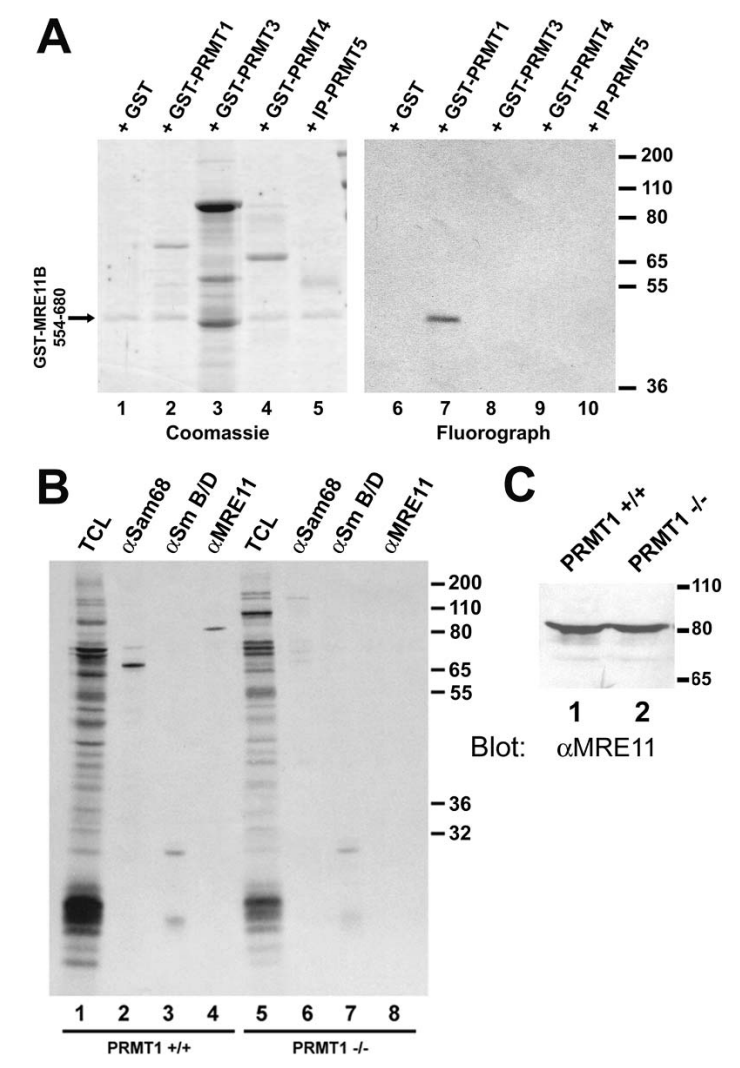

Figure 2. Arginine methylation of MRE11 by PRMT1. (A) Recombinant GST-PRMTs or PRMT5 immunoprecipitated from HeLa cells were incubated with GST-MRE11 (554-680) in the presence of $\left[{ }^{3} \mathrm{H}\right]$-AdoMet as the methyl donor. Proteins were separated by SDSPAGE and visualized by Coomassie staining (left) and the $\left[{ }^{3} \mathrm{H}\right]-$ labeled proteins visualized by fluorography (right). (B) $\mathrm{PRMT1}^{+/+}$and $\mathrm{PRMT1}^{-/-}$were metabolically labeled with [methyl- $\left.{ }^{3} \mathrm{H}\right]-L$-methionine, and cell lysates were immunoprecipitated with Sam68, Sm (Ana128; Cappel), or MRE11 antibodies. The in vivo methylated proteins were visualized by fluorography after SDS-PAGE. (C) Equivalent amount of TCL from normal ES cells or ES cells $\mathrm{PRMT1}^{-1-}$ was immunoblotted with anti-MRE11 antibodies.

\section{MRE11 is arginine methylated by PRMT1}

To identify the PRMT that methylates MRE11, an in vitro methylation assay was performed using $\left[{ }^{3} \mathrm{H}\right]$ AdoMet. A recombinant glutathione-S-transferase (GST) MRE11 fusion protein containing the amino acids 554680 of MRE11 encompassing the GAR domain was methylated by PRMT1 but not by PRMT3, PRMT4, and PRMT5 (Fig. 2A). All the methyltransferases were active when incubated with known substrates (data not shown). Active PRMT5 was immunoprecipitated from HeLa cells using an anti-PRMT5 antibody as described (Boisvert et al. 2002). PRMT1 is required for embryogenesis as PRMT1 ${ }^{-1-}$ mice are early embryonic lethal; however, embryonic stem (ES) cells devoid of PRMT1 are viable (Pawlak et al. 2000). To determine whether PRMT1 was the physiological enzyme methylating MRE11, the methylation of endogenous MRE11 was compared between PRMT1 $1^{+/+}$and $P R M T 1^{-/-}$ES cell extracts. The cells were metabolically labelled $24 \mathrm{~h}$ after transfection with $\mathrm{L}-\left[\right.$ methyl- $\left.{ }^{3} \mathrm{H}\right]$-methionine for $3 \mathrm{~h}$ in the presence cycloheximide and chloramphenicol to ensure incorporation into methyl groups and not during protein synthesis as described (Boisvert et al. 2002). Im- 
munoprecipitations in ES cells were performed with the indicated antibody and the labelled methylated protein separated by SDS-PAGE and visualized by fluorography. MRE11 was methylated in $\mathrm{PRMT}^{+/+}$ES cells but not in PRMT1 ${ }^{-1-}$ ES cells (Fig. 2B, lanes 4,8). Sam68, a known PRMT1 substrate (Cote et al. 2003), was employed as a positive control, and its methylation was lost in PRMT1 ${ }^{-/}$ES cells (Fig. 2B, lanes 2,6). SmB/D, known substrates of PRMT5 (Fig. 2B, lanes 3,7), remained methylated in PRMT1 ${ }^{-/-}$cells as expected. Although the methylation was generally lower in $\mathrm{PRMT}^{-/-}$cells (Fig. 2B, lanes 1,5), MRE11 protein expression remained equivalent between the ES cell lines (Fig. 2C). Taken together, our results demonstrate that MRE11 is arginine methylated within the GAR domain by PRMT1.

\section{Arginines within the GAR domain are necessary for MRE11 exonuclease activity}

The 3 ' -5 ' exonuclease activity is one of the most important biochemical features of MRE11 (Paull and Gellert 1998). To investigate whether the GAR domain affected the enzymatic activity of MRE11, two mutant MRE11 proteins were generated where the arginines between residues 570 and 594 were replaced with alanines (R/A) or lysines (R/K). MRE11 wild-type, R/A, and R/K baculoviruses were generated, and the corresponding proteins were purified to homogeneity from insect cells, a species known to contain PRMTs (Boulanger et al. 2004). Purified human MRE11 was methylated as analyzed by mass spectrometry (data not shown) and was recognized by ASYM25, unlike the $\mathrm{R} / \mathrm{A}$ and $\mathrm{R} / \mathrm{K}$ mutant proteins, which were not significantly methylated (Fig. 3A). All MRE11 proteins associated with RAD50 and NBS1, as observed in anti-NBS1 immunoprecipitates, demonstrating that the GAR domain does not influence the formation of the MRN complex (Fig. 3B). When compared with wild type, the exonuclease activity of MRE11 on double-stranded DNA was absent for the R/A mutant. These data demonstrate that either the charge or the methyl groups on the arginines are required (Fig. 3C, MRE11 R/A). Amino acid substitution of arginines to lysines to maintain the charge severely impaired the exonuclease activity, demonstrating that the arginines or methylarginines are necessary for optimal MRE11 activity (Fig. 3C, MRE11 R/K). At $2.5 \mathrm{nM}$ the $\mathrm{R} / \mathrm{K}$ appears more active, but it lacks the processivity to cleave the DNA into smaller fragments, unlike the wild-type MRE11 (Fig. 3C). Hypomethylated MRE11 could not be obtained and assayed for exonuclease activity because insect cells are hypersensitive to methylase inhibitors (data not shown). Our findings suggest that the MRE11 GAR domain regulates the exonuclease activity, an enzymatic activity important for the checkpoint response (Uziel et al. 2003).

\section{Inhibition of MRE11 methylation results in S-phase checkpoint defects}

A-TLD cells are known to display intra-S-phase checkpoint defects and fail to suppress DNA synthesis in response to DNA damage (Stewart et al. 1999). To examine whether cells pretreated with the methyl-thio-adenosine (MTA) methylase inhibitor exhibited a similar phenotype, we examined the ability of the cells to progress
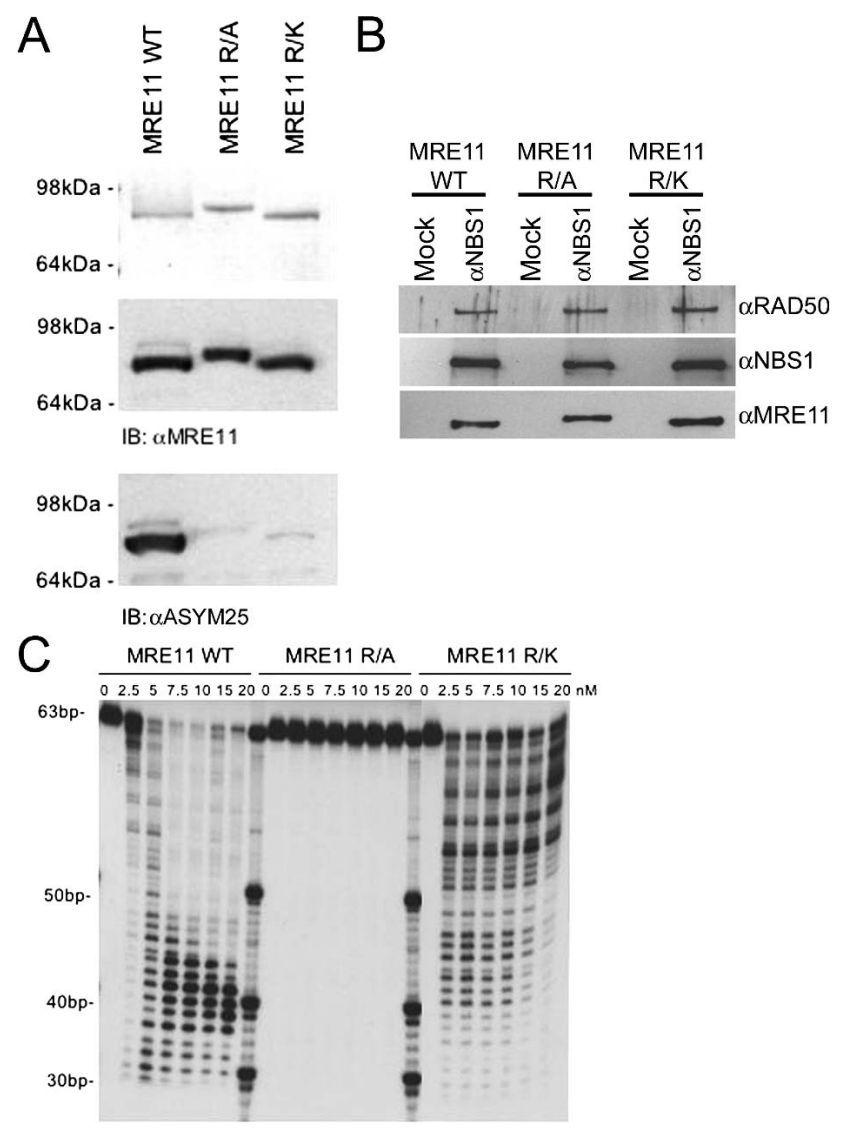

Figure 3. The MRE11 GAR domain regulates the exonuclease activity. (A) HIS-tagged human MRE11 wild-type, R/A, and R/K baculoviruses were generated, and the corresponding proteins were purified to homogeneity from insect cells. Purified MRE11, MRE11R/ $\mathrm{A}$, and MRE11R/K were visualized by Coomassie blue (top panel) and immunoblotted with MRE11 (middle panel) and ASYM25 (bottom panel). $(B)$ To determine whether the methylated arginines are necessary for the formation of the MRN complex, cells infected with NBS1, RAD50, and either MRE11, MRE11R/A, or MRE11R/K baculoviruses were lysed and immunoprecipitated with beads alone or anti-NBS1 antibodies. The presence of RAD50 and MRE11 as well as NBS1 was visualized by immunoblotting. Their identities are indicated on the right. $(C)$ Nuclease assays were performed with the indicated amount of each of MRE11 WT, MRE11R/A, or MRE11R/ $\mathrm{K}$, in $5 \mathrm{mM} \mathrm{MnCl}_{2}$ on a $\left[{ }^{32} \mathrm{P}\right]-5$ '-labeled at one end 63-bp dsDNA substrate. Reactions were incubated for $60 \mathrm{~min}$ at $37^{\circ} \mathrm{C}$ before separation on a $10 \%$ denaturing polyacrylamide gel and visualized by autoradiography.

through S phase following DNA damage. Indeed, $\sim 70 \%$ of HeLa cells and CRL2097 (data not shown) pretreated with MTA progressed through the S-phase-like A-TLDderived cells following DNA damage (Fig. 4A). In contrast, $\sim 40 \%$ mock-treated HeLa cells progressed through $S$ phase following DNA damage (Fig. 4A). Since MTA has a broad specificity, we down-regulated the expression of PRMT1 using siRNA generated by pBS/U6 (Rezai-Zadeh et al. 2003). The PRMT1 expression was down-regulated by $\sim 70 \%$ in HeLa cells, and the methylation of MRE11 Arg587 was severely impaired in these cells, as detected by immunoblotting with $\alpha$ Arg587 (Fig. 4B), an antiaDMA 587 site-specific MRE11 antibody that we generated (Supplementary Fig. 1C). The hypomethylation of MRE11 was also observed with ASYM25 (data not shown). The PRMT1 siRNA-treated cells displayed a 
Boisvert et al.

A

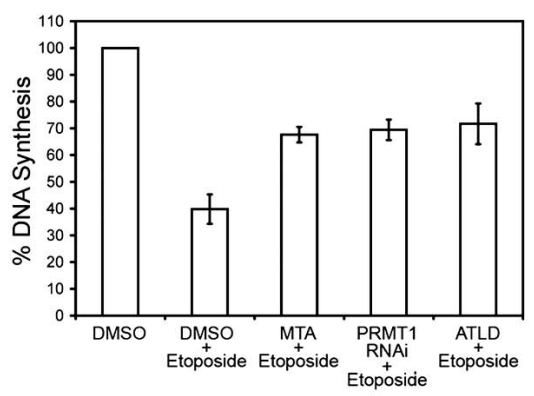

B

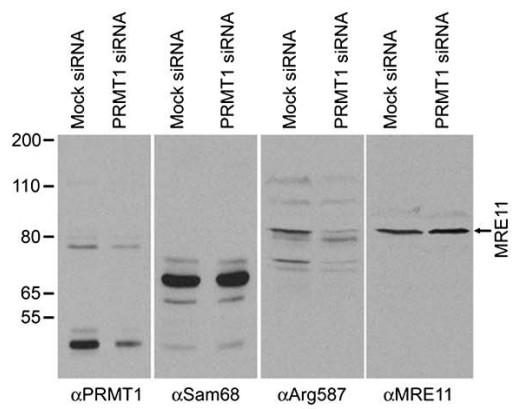

C
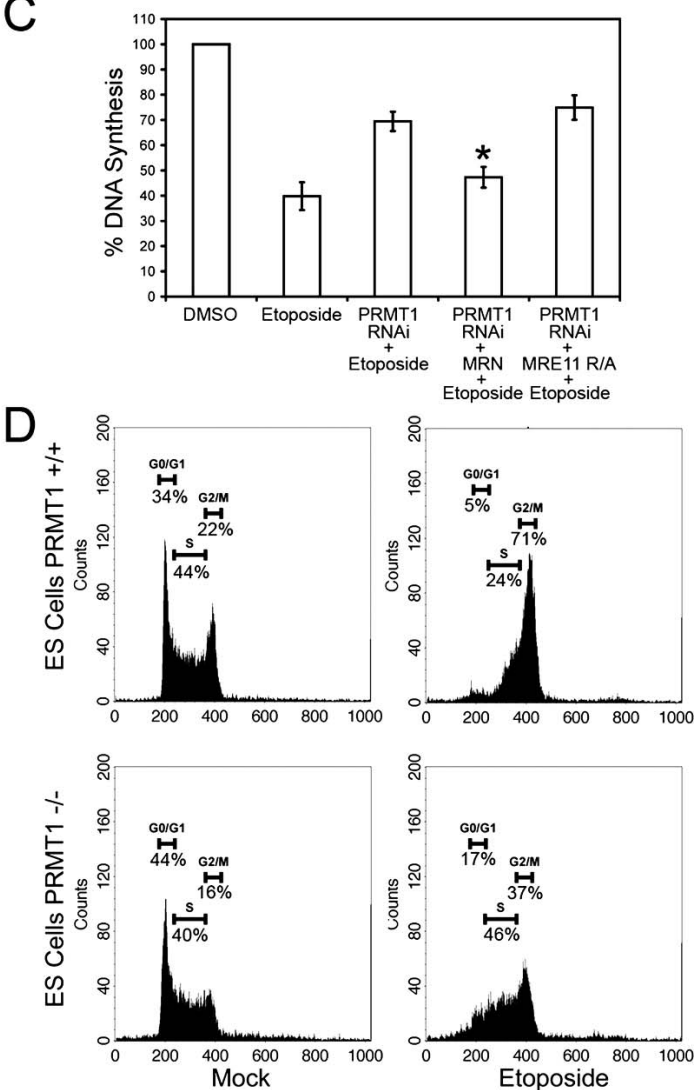

Figure 4. Arginine methylation of MRE11 regulates the intra-S-phase checkpoint. (A) DNA synthesis following DNA damage in HeLa cells pretreated with the methylase inhibitor MTA, in cells treated with PRMT1-siRNA, or in A-TLD cells. DNA synthesis was assessed $1 \mathrm{~h}$ after $50 \mu \mathrm{M}$ etoposide treatment. The results represent an average of six independent experiments. $(B)$ Cell extracts from mock- and PRMT1-siRNAtransfected HeLa cells were resolved by SDS-PAGE, transferred to nitrocellulose, and immunoblotted with PRMT1, Sam68, Arg587, and MRE11 antibodies as indicated. $(C)$ DNA synthesis following DNA damage in PRMT1-siRNA cells protein transfected with 100 ng of the MRE11 complex (MRN) or MRE11 R/A alone using Chariot. DNA synthesis was assessed $1 \mathrm{~h}$ after $50 \mu \mathrm{M}$ etoposide treatment. The results represent an average of six independent experiments. The asterisk represents a significant difference between PRMT1 RNAi and PRMT1 RNAi + MRN $(P<0.01)$. $(D)$ S-phase progression was followed using flow cytometry of PRMT1 $1^{+/}$ES cells (top panels) or PRMT1 ${ }^{-/-}$ES cells (bottom panels) $16 \mathrm{~h}$ following either mock treatment (left panels) or DNA damage induced with a low dose of $500 \mathrm{nM}$ etoposide (right panels). The percentage of cells in the $G_{0} / G_{1}, S$, or $G_{2} / M$ phases of the cell cycle is indicated.

phenotype similar to MTA and A-TLD cells treated with etoposide (Fig. 4A). Since PRMT1 methylates many substrates, we purified and introduced the MRN complex into the cells by protein transduction with Chariot. The MRN complex containing methylated MRE11 to a large extent rescued the PRMT1 siRNA phenotype, and this effect was dose-dependent (Fig. 4C; Supplementary 3A). The introduction of equal amounts of purified MRE11 R/A alone (Fig. 4C) or control immunoglobulin G (Supplementary Fig. 3B) did not rescue the intra-S-phase defect in PRMT1 siRNA-treated cells. These findings demonstrate that arginine methylation of MRE11 by PRMT1 is required for the intra-S-phase DNA damage checkpoint. To determine the effect of DNA damage on cell cycle profiles, $\mathrm{PRMT1}^{-1-}$ ES cells were exposed to a low dose of etoposide $(500 \mathrm{nM})$. The ability to repair the damaged DNA and progress through the cell cycle were assessed $16 \mathrm{~h}$ after damage. Approximately $24 \%$ of the wild-type ES cells remained in the S phase and $70 \%$ were in the $\mathrm{G}_{2} / \mathrm{M}$ phase, while $46 \%$ of the PRMT1 ${ }^{-/-}$cells remained accumulated in S phase and $37 \%$ progressed to the $G_{2} / M$ phase following DNA damage (Fig. 4D). These findings suggest that $\mathrm{PRMT1}^{-/-}$ES cells progress slower through the $S$ phase than PRMT1 ${ }^{+/+}$cells following DNA damage.

In this study, we provide evidence that MRE11 is arginine methylated by PRMT1. First, we showed that the aDMA-specific ASYM25 antibody and Arg587 MRE11 site-specific antibody directly recognized MRE11 by immunoblotting. It was also shown that MRE11 incorporated $\left[{ }^{3} \mathrm{H}\right]$-methyl groups in a known in vivo methylation assay, and this incorporation was absent in PRMT1 $1^{-/}$ cells. It was also shown that the MRE11 GAR domain was methylated by PRMT1 in vitro. Lastly, we identified by MALDI-TOF that peaks that corresponded to the mass of methylated MRE11 peptides and most of the peptide peaks were less abundant or totally absent in the MTA-treated cells (data not shown). The identification by mass spectrometry of multiple methylated peptides corresponding to MRE11 and the low abundance of unmethylated peptides within the GAR domain suggest that MRE11 exists predominantly in the methylated form. By using the methyl-specific antibodies Arg587 and ASYM25, we observed no difference in MRE11 methylation or global methylation following genotoxic treatments (data not shown). Similarly, the methylation 
of histone H3 Lys 79, involved in the recruitment of 53BP1 to sites of DNA damage, is not regulated with DNA damage (Huyen et al. 2004). Cells harboring mutations in ATM, MRE11, or NBS1 (Savitsky et al. 1995; Carney et al. 1998; Varon et al. 1998; Stewart et al. 1999) or cells down-regulated in the protein MDC1 (Goldberg et al. 2003; Lou et al. 2003; Stewart et al. 2003) display intra-S-phase checkpoint defects. Our study suggests a role for arginine methylation and PRMT1 in this process. Cells pretreated with methyltransferase inhibitors displayed an intra-S-phase defect following DNA damage, demonstrating a requirement for methylation in this response. As methyltransferase inhibitors have a broad specificity, other type of methylation events cannot be ruled out solely based on this observation. The PRMT1 siRNA-treated cells displayed an intra-S-phase checkpoint defect similar to that of MTA-treated cells, narrowing down the observed phenotype to the inhibition of PRMT1 activity. Moreover, PRMT1 ${ }^{-/-}$ES cells displayed a slower progression through $S$ phase following DNA damage. Based on these experiments, it is likely that several methylated proteins contribute to this intra-Sphase checkpoint defect. However, we have shown that reintroduction of the purified arginine-methylated baculovirus produced MRN complex into PRMT1 siRNAtreated cells significantly rescued the phenotype. These findings demonstrate that the MRN complex can alleviate the intra-S-phase checkpoint defect observed in these cells. Collectively, our results suggest that the arginine methylation may regulate the MRE11 exonuclease activity during the intra-S-phase checkpoint response. In summary, the results presented herein suggest that arginine methylation, a poorly characterized post-translational modification, plays a crucial role in regulating the DNA damage response.

\section{Materials and methods}

\section{Antibodies}

The peptides used to generate rabbit antibodies against MRE11 and methylated 587 MRE11 were as follows: MRE11 (amino acids 597-621) (kstrqqpsrnvttknysevievdes) and Arg587 (KGQNSASR *GGSQRGR), where the arginine marked with an asterisk is aDMA. Antibodies against PRMT1 and Sam68, SYM10 were from Upstate Biotechnology, and antiNBS1 and anti-RAD50 were from Novus Biologicals.

DNA constructs

The full-length human MRE11 was amplified by PCR from HeLa cells cDNA and cloned in pFAST-Bacl. The arginine-to-alanine MRE11 mutations were generated by ligating double-stranded oligonucleotides with the sequence 5'-GGAGCAGGCGCAGGAGCAGGTGCAGCAGGTGG AGCAGGGCAAAATTCAGCATCGGCAGGAGGGTCTCAAGCAGG AGCA- ${ }^{\prime}$, and the arginine to lysine MRE11 mutation was generated by ligating 5'-GGAAAAGGCAAAGGAAAAGGTAAGAAAGGTGGAAA AGGGCAAAATT CAGCATCGAAA GGAGGGTCTCAAAAAGGAAA G-3' into a SmaI site created by inverse PCR using the following oligonucleotides 5 '-TCCCCCGGGGTTGGTTGCTGCTGAGATGCTATC$3^{\prime}$ and $5^{\prime}$-TCCCCCGGGGACACTGGTCTGGAGACTTCTACC-3'.

\section{Mass spectrometry}

Endogenous MRE11 was immunopurified from $5 \times 10^{8}$ HeLa cells by using $1 \mathrm{mg}$ of our rabbit anti-MRE11 antibody coupled to $1 \mathrm{~g}$ of protein A-Sepharose (Sigma-Aldrich). After extensive washings with lysis buffer and $1 \times$ phosphate-buffered saline (PBS), the bound proteins were eluted with $250 \mu \mathrm{M}$ of the MRE11 peptide in 1× PBS. Eluted proteins were resolved by SDS-PAGE and revealed by Coomassie blue staining. The apparent bands were excised, in-gel digested with trypsin, and analyzed by MALDI-TOF analysis on a Voyager DE-STR mass spectrometer (University of Calgary, Alberta).
Methylation assays

GST-MRE11 (554-680; from M. Bedford, University of Texas, Smithville, TX) was incubated with GST-PRMT1, GST-PRMT3, GST-PRMT4 or with immunoprecipitated PRMT5 with $0.55 \mu \mathrm{Ci}$ of [methyl $-{ }^{3} \mathrm{H}$ ] AdoMet in the presence of $25 \mathrm{mM}$ Tris- $\mathrm{HCl}$ at $\mathrm{pH} 7.5$ for $1 \mathrm{~h}$ at $37^{\circ} \mathrm{C}$ in a final volume of $30 \mu \mathrm{L}$. Reactions were stopped by adding $20 \mu \mathrm{L}$ of $2 \times$ SDSPAGE sample buffer, followed by heating at $100^{\circ} \mathrm{C}$ for $10 \mathrm{~min}$. Samples were loaded on $9 \%$ SDS-polyacrylamide gels and stained with Coomassie blue. The destained gels were soaked in EN $^{3}$ HANCE (PerkinElmer Life Sciences) according to manufacturer instructions and visualized by fluorography. The in vivo methylation assay was performed by metabolically labeling the cells with $\mathrm{L}-\left[\right.$ methyl- $\left.{ }^{3} \mathrm{H}\right]$ methionine directly in methioninefree medium for $3 \mathrm{~h}$ in the presence of cycloheximide and chloramphenicol, as described previously (Boisvert et al. 2002). L- $\left[{ }^{35}\right.$ S]methionine was also used as a control under the same conditions to exclude incorporation during protein synthesis (data not shown). The cell lysates were immunoprecipitated, and the ${ }^{3} \mathrm{H}$-labeled proteins were visualized by fluorography after SDS-PAGE.

Purification of MRE11 from insect cells and exonuclease assays Recombinant MRE11-His ${ }_{6}$, MRE11R/A-His ${ }_{6}$, or MRE11R/K-His 6 proteins were produced from baculovirus-infected Sf9 cells, using the Bacto-Bac expression system (Invitrogen). Five-hundred-milliliter spinner flasks of Sf9 cells $\left(1 \times 10^{6}\right.$ per milliliter $)$ infected with MRE11, MRE11R/ A, or MRE11R/K baculoviruses (M.O.I. 10) for $2 \mathrm{~d}$ at $27^{\circ} \mathrm{C}$ as described (Paull and Gellert 1998; Masson et al. 2001). Reactions contained $100 \mathrm{nM}$ DNA in MOPS buffer $(25 \mathrm{mM}$ MOPS at $\mathrm{pH} 7.0,60 \mathrm{mM} \mathrm{KCl}, 0.2 \%$ Tween-20, $2 \mathrm{mM} \mathrm{DTT}$, and $5 \mathrm{mM} \mathrm{MnCl}_{2}$ ). After $5 \mathrm{~min}$ at $37^{\circ} \mathrm{C}$, the indicated amount of MRE11, MRE11R/A, or MRE11R/K was added, and incubation was continued for $1 \mathrm{~h}$. Reaction products were analyzed by $10 \%$ urea-PAGE using followed by autoradiography.

Intra-S-phase checkpoint assays and protein transduction

HeLa cells treated for $24 \mathrm{~h}$ with $750 \mu \mathrm{M}$ MTA or PRMT1-down-regulated with siRNA or pure proteins introduced with Chariot were labeled with $20 \mathrm{nCi} / \mathrm{mL}\left[{ }^{14} \mathrm{C}\right]$ thymidine for $24 \mathrm{~h}$, washed, and incubated for an additional $24 \mathrm{~h}$. The cells were DNA damaged with $50 \mu \mathrm{M}$ etoposide for $1 \mathrm{~h}$ and labeled with $2.5 \mu \mathrm{Ci} / \mathrm{mL}\left[{ }^{3} \mathrm{H}\right]$-thymidine for $45 \mathrm{~min}$. Inhibition of DNA synthesis was measured as described (Falck et al. 2002). Protein transduction was performed according to the manufacturer protocol using $100 \mathrm{ng}$ of MRN complex or MRE11 R/A purified from insect cells or control immunoglobulin $\mathrm{G}$ and $6 \mu \mathrm{L}$ of Chariot (ActiveMotif).

\section{Acknowledgments}

We thank M. Bedford, M. Hendzel, A. Koromilas, M. Loignon, E. Ruley, E. Seto, T. Paull, J. Petrini, M. Weinfeld, and Y. Zhang for helpful discussions and/or reagents, and P. Cléroux for technical help. This work was supported by grant \#MOP-67070 from the Canadian Institutes of Health Research (CIHR) to S.R., and the National Cancer Institute of Canada (NCIC) to J.Y.M. F.-M.B. is a recipient of a studentship from the NCIC and U.D. is a recipient of a FRSQ Ph.D. scholarship. J.Y.M is a CIHR new Investigator and S.R. is a CIHR Investigator.

\section{References}

Bachand, F. and Silver, P.A. 2004. PRMT3 is a ribosomal protein methyltransferase that affects the cellular levels of ribosomal subunits. EMBO J. 23: 2641-2650.

Bedford, M.T., Frankel, A., Yaffe, M.B., Clarke, S., Leder, P., and Richard, S. 2000. Arginine methylation inhibits the binding of proline-rich ligands to Src homology 3, but not WW, domains. J. Biol. Chem. 275: 16030-16036.

Boisvert, F.M., Cote, J., Boulanger, M.C., Cleroux, P., Bachand, F., Autexier, C., and Richard, S. 2002. Symmetrical dimethylarginine methylation is required for the localization of SMN in Cajal bodies and pre-mRNA splicing. J. Cell. Biol. 159: 957-969.

Boisvert, F.M., Cote, J., Boulanger, M.C., and Richard, S. 2003. A proteomic analysis of arginine-methylated protein complexes. Mol. Cell. Proteomics 2: 1319-1330.

Boulanger, M.C., Miranda, T.B., Clarke, S., Di Fruscio, M., Suter, B., Lasko, P., and Richard, S. 2004. Characterization of the Drosophila protein arginine methyltransferases DART1 and DART4. Biochem. J. 379: 283-289. 
Carney, J.P., Maser, R.S., Olivares, H., Davis, E.M., Le Beau, M., Yates III, J.R., Hays, L., Morgan, W.F., and Petrini, J.H. 1998. The hMrel1/ hRad50 protein complex and Nijmegen breakage syndrome: Linkage of double-strand break repair to the cellular DNA damage response. Cell 93: 477-486.

Carson, C.T., Schwartz, R.A., Stracker, T.H., Lilley, C.E., Lee, D.V., and Weitzman, M.D. 2003. The Mrell complex is required for ATM activation and the $\mathrm{G}_{2} / \mathrm{M}$ checkpoint. EMBO J. 22: 6610-6620.

Chen, D., Ma, H., Hong, H., Koh, S.S., Huang, S.M., Schurter, B.T. Aswad, D.W., and Stallcup, M.R. 1999. Regulation of transcription by a protein methyltransferase. Science 284: 2174-2177.

Cote, J., Boisvert, F.M., Boulanger, M.C., Bedford, M.T., and Richard, S. 2003. Sam68 RNA binding protein is an in vivo substrate for protein arginine N-methyltransferase 1. Mol. Biol. Cell. 14: 274-287.

Cuthbert, G.L., Daujat, S., Snowden, A.W., Erdjument-Bromage, H., Hagiwara, T., Yamada, M., Schneider, R., Gregory, P.D., Tempst, P., Bannister, A.J., et al. 2004. Histone deimination antagonizes arginine methylation. Cell 118: 545-553.

de Jager, M., van Noort, J., van Gent, D.C., Dekker, C., Kanaar, R., and Wyman, C. 2001. Human Rad50/Mre11 is a flexible complex that can tether DNA ends. Mol. Cell 8: 1129-1135.

Falck, J., Petrini, J.H., Williams, B.R., Lukas, J., and Bartek, J. 2002. The DNA damage-dependent intra-S phase checkpoint is regulated by parallel pathways. Nat. Genet. 30: 290-294.

Friesen, W.J., Massenet, S., Paushkin, S., Wyce, A., and Dreyfuss, G. 2001. SMN, the product of the spinal muscular atrophy gene, binds preferentially to dimethylarginine-containing protein targets. Mol. Cell 7: 1111-1117.

Gary, J.D. and Clarke, S. 1998. RNA and protein interactions modulated by protein arginine methylation. Prog. Nucleic Acid Res. Mol. Biol. 61: $65-131$.

Goldberg, M., Stucki, M., Falck, J., D'Amours, D., Rahman, D., Pappin D., Bartek, J., and Jackson, S.P. 2003. MDCl is required for the intraS-phase DNA damage checkpoint. Nature 421: 952-956.

Hopfner, K.P., Craig, L., Moncalian, G., Zinkel, R.A., Usui, T., Owen, B.A., Karcher, A., Henderson, B., Bodmer, J.L., McMurray, C.T., et al. 2002. The Rad50 zinc-hook is a structure joining Mre11 complexes in DNA recombination and repair. Nature 418: 562-566.

Huyen, Y., Zgheib, O., Ditullio Jr., R.A., Gorgoulis, V.G., Zacharatos, P., Petty, T.J., Sheston, E.A., Mellert, H.S., Stavridi, E.S., and Halazonetis, T.D. 2004. Methylated lysine 79 of histone H3 targets 53BP1 to DNA double-strand breaks. Nature 432: 406-411.

Kwak, Y.T., Guo, J., Prajapati, S., Park, K.J., Surabhi, R.M., Miller, B., Gehrig, P., and Gaynor, R.B. 2003. Methylation of SPT5 regulates its interaction with RNA polymerase II and transcriptional elongation properties. Mol. Cell 11: 1055-1066.

Lee, J.H. and Paull, T.T. 2004. Direct activation of the ATM protein kinase by the Mre11/Rad50/Nbsl complex. Science 304: 93-96.

Lisby, M., Barlow, J.H., Burgess, R.C., and Rothstein, R. 2004. Choreography of the DNA damage response: Spatiotemporal relationships among checkpoint and repair proteins. Cell 118: 699-713.

Lou, Z., Minter-Dykhouse, K., Wu, X., and Chen, J. 2003. MDC1 is coupled to activated CHK2 in mammalian DNA damage response pathways. Nature 421: 957-961.

Masson, J.Y., Tarsounas, M.C., Stasiak, A.Z., Stasiak, A., Shah, R., McIlwraith, M.J., Benson, F.E., and West, S.C. 2001. Identification and purification of two distinct complexes containing the five RAD51 paralogs. Genes \& Dev. 15: 3296-3307.

McBride, A.E. and Silver, P.A. 2001. State of the arg: Protein methylation at arginine comes of age. Cell 106: 5-8.

Nelms, B.E., Maser, R.S., MacKay, J.F., Lagally, M.G., and Petrini, J.H. 1998. In situ visualization of DNA double-strand break repair in human fibroblasts. Science 280: 590-592.

Paull, T.T. and Gellert, M. 1998. The 3' to 5' exonuclease activity of Mre 11 facilitates repair of DNA double-strand breaks. Mol. Cell 1: 969-979.

Pawlak, M.R., Scherer, C.A., Chen, J., Roshon, M.J., and Ruley, H.E. 2000. Arginine N-methyltransferase 1 is required for early postimplantation mouse development, but cells deficient in the enzyme are viable. Mol. Cell Biol 20: 4859-4869.

Rezai-Zadeh, N., Zhang, X., Namour, F., Fejer, G., Wen, Y.D., Yao, Y.L., Gyory, I., Wright, K., and Seto, E. 2003. Targeted recruitment of a histone H4-specific methyltransferase by the transcription factor YY1. Genes \& Dev. 17: 1019-1029.
Savitsky, K., Bar-Shira, A., Gilad, S., Rotman, G., Ziv, Y., Vanagaite, L., Tagle, D.A., Smith, S., Uziel, T., Sfez, S., et al. 1995. A single ataxia telangiectasia gene with a product similar to PI-3 kinase. Science 268: $1749-1753$.

Shiloh, Y. 2003. ATM and related protein kinases: Safeguarding genome integrity. Nat. Rev. Cancer 3: 155-168.

Stewart, G.S., Maser, R.S., Stankovic, T., Bressan, D.A., Kaplan, M.I., Jaspers, N.G., Raams, A., Byrd, P.J., Petrini, J.H., and Taylor, A.M. 1999. The DNA double-strand break repair gene hMRE11 is mutated in individuals with an ataxia-telangiectasia-like disorder. Cell 99: $577-587$.

Stewart, G.S., Wang, B., Bignell, C.R., Taylor, A.M., and Elledge, S.J. 2003. MDC1 is a mediator of the mammalian DNA damage checkpoint. Nature 421: 961-966.

Swiercz, R., Person, M.D., and Bedford, M.T. 2005. Ribosomal protein S2 is a substrate for mammalian protein arginine methyltransferase 3 (PRMT3). Biochem. J. 386: 85-91.

Theunissen, J.W., Kaplan, M.I., Hunt, P.A., Williams, B.R., Ferguson, D.O., Alt, F.W., and Petrini, J.H. 2003. Checkpoint failure and chromosomal instability without lymphomagenesis in Mre11(ATLD1/ ATLD1) mice. Mol. Cell 12: 1511-1523.

Uziel, T., Lerenthal, Y., Moyal, L., Andegeko, Y., Mittelman, L., and Shiloh, Y. 2003. Requirement of the MRN complex for ATM activation by DNA damage. EMBO J. 22: 5612-5621.

van den Bosch, M., Bree, R.T, and Lowndes, N.F. 2003. The MRN complex: Coordinating and mediating the response to broken chromosomes. EMBO Rep. 4: 844-849.

Varon, R., Vissinga, C., Platzer, M., Cerosaletti, K.M., Chrzanowska, K.H., Saar, K., Beckmann, G., Seemanova, E., Cooper, P.R., Nowak, N.J., et al. 1998. Nibrin, a novel DNA double-strand break repair protein, is mutated in Nijmegen breakage syndrome. Cell 93: 467476.

Wang, H., Huang, Z.Q., Xia, L., Feng, Q., Erdjument-Bromage, H., Strahl, B.D., Briggs, S.D., Allis, C.D., Wong, J., Tempst, P., et al. 2001. Methylation of histone $\mathrm{H} 4$ at arginine 3 facilitating transcriptional activation by nuclear hormone receptor. Science 293: 853-857.

Wang, Y., Wysocka, J., Sayegh, J., Lee, Y., Perlin, J., Leonelli, L., Sonbuchner, L., McDonald, C., Cook, R., Dou, Y., et al. 2004. Human PAD4 regulates histone arginine methylation levels via demethylimination. Science 306: 279-283.

Yu, M.C., Bachand, F., McBride, A.E., Komili, S., Casolari, J.M., and Silver, P.A. 2004. Arginine methyltransferase affects interactions and recruitment of mRNA processing and export factors. Genes \& Dev. 18: $2024-2035$

Yun, C.Y. and Fu, X.D. 2000. Conserved SR protein kinase functions in nuclear import and its action is counteracted by arginine methylation in Saccharomyces cerevisiae. J. Cell. Biol. 150: 707-718. 


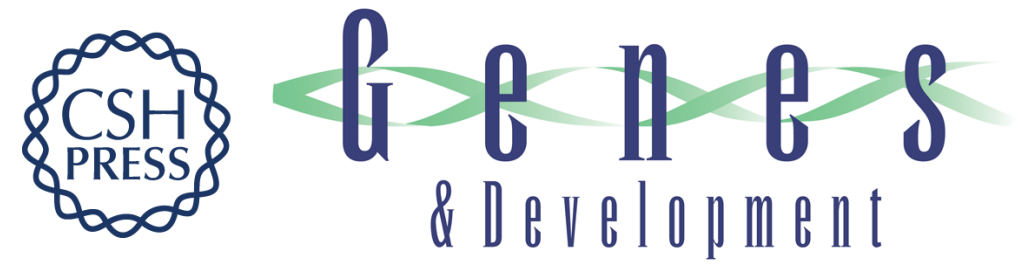

\section{Arginine methylation of MRE11 by PRMT1 is required for DNA damage checkpoint control}

François-Michel Boisvert, Ugo Déry, Jean-Yves Masson, et al.

Genes Dev. 2005, 19:

Access the most recent version at doi:10.1101/gad.1279805

\section{Supplemental http://genesdev.cshlp.org/content/suppl/2005/03/02/gad.1279805.DC1 Material}

References This article cites 40 articles, 19 of which can be accessed free at: http://genesdev.cshlp.org/content/19/6/671.full.html\#ref-list-1

\section{License}

Email Alerting

Receive free email alerts when new articles cite this article - sign up in the box at the top Service



